\title{
Impact of fuel energy prices in Tunisia
}

\author{
Lassaad Jebali ${ }^{1}$, Anis Kacem ${ }^{2}$ \\ ${ }^{1}$ University of Tunis, ISG of Tunis and LIERI (FSEGT), TUNISA \\ ${ }^{2}$ The International Academy of Governance, TUNISA \\ lassaad.jebali@gmail.com
}

\begin{abstract}
The policy of subsidizing petroleum derivatives in Tunisia distorts the real prices of goods and services. It does not take care on environment. There is no serious fiscal policies to reduce pollution generated by energy products.

The calculation of the correlation matrix between different macroeconomic aggregates does not give a negative effect of oil prices on national GDP. However, this result is serious, because the impact on economic (performance) is hidden, affecting first the general level of prices, unemployment and inflation. Instability of oil prices has no apparent impact. This fact and instability make many difficulties to manage prices and inflation after revolution. Impact on GDP passes through Economic Vulnerability Indicator (EVI) and agricultural sector.
\end{abstract}

Keywords: upward oil price days, Tunisian GDP, hidden impact, curve shifts, EVI

Received: 28/03/2018 - Accepted: 30/05/2018

\section{Introduction}

A large number of studies have investigated the direct and hidden impact of oil prices on economies. Most studies have adopted VAR models to capture crud price impact on groups of countries. These researches have been able to calculate the effects of energy through elasticities. However, a (reduced) number of studies have calculated the hidden effects of fuel volatility with subsidy policies without consideration of negative externalities on environment

This paper tries to capture the effects of crude oil price volatility on an economy that subsidizes petroleum derivatives and has not a clear environmental policy. We try to answer the following question: what are the (direct) and hidden impacts of oil volatility on the Tunisian economy?

Tunisia produces, export crude oil and import petroleum derivatives (diesel, gasoline, kerosene). Oil shocks and price increases in the world market. It has impacts on the macroeconomic aggregates of Tunisia and on the Tunisian social welfare. These impacts are indirect for the Tunisian case. Indeed, in this paper, we show that the number of days in which the price of crude increases has not a negative effect on the national GDP and the correlation is low and positive. However, the effect of fuel prices is significant on the other macroeconomic aggregates as inflation.

The high volatility of fuel prices makes the Tunisian economy more vulnerable through the agricultural sector. We explain this idea by introducing the variable EVI that measures the vulnerability of the Tunisian economy.
This paper aims to detect the hidden and apparent effects of energy on the Tunisian economy given the institutional change of 2011 and the political change. We organize this into five sections:

With the first one, we develop the concept of Oil shocks via the supply and demand curves shifts. Second, we analyze Economic Growth and oil shocks. The Third section develops the Welfare hidden Impact of oil prices. Forth, we give attention to the macroeconomic transmission channels of oil price shocks. In the last section we analyses the case study of Tunisia and we conclude.

\section{Oil shocks: the supply and demand curves shifts}

We can define an oil shock by a large modification in oil prices, in the international market, and the supply. These variations may occur slowly and gradually or abruptly and unexpectedly. Petroleum, as a substantial source of energy, affects energy prices directly. When the price of the crude increases in the world market, energy prices rise and vice versa, even with subsides policies. Moreover, when the price of oil increases, the demand for other sources of energy indirectly increase; in such a case, the price of other competitor sources which would be supplied as a new source of energy, will rise. Consequently, an oil price shock is more generally an energy and agricultural sector price shock, and an energy and agricultural crisis are directly influenced by an oil crisis. 
Three oil shocks or energy shocks occurred in 1973 and in 1990 (Iraq and NATO war). As it is clear, the reason for these three main oil shocks was supply disruption.

The oil price shocks of the 1970s can be explained by pure supply factors, but starting from the 1980s oil price increasingly began to come under another pressure from its demand side. It accelerated from about US $\$ 35 /$ barrel in 1981 to beyond US\$120/barrel in 2013. At the same time federal interest rates decreased from 16.7 percent per year to about 0.1 percent. Taghizadeh and Yoshino (2015) explain how this long-term price increase was, in most cases, caused by expansionary monetary policies that heightened oil prices through interest rate channels, and so the change rate. For the case of developing country, inflation has an energy dimension (imported inflation) according to banking interest rates. Aggressive monetary policies stimulated oil demand and blew up the oil price. Consequently there will be slower economic growth. This means that there are also many demand factors that affect consumption of oil.

This idea can be more expressed using the aggregate supply and demand model, which explains economic fluctuations in the short run. We can show, via the aggregate and supply curve, that an oil shock do not cause only shift on the supply curve but on the demand curve simultaneously. Consequently, production and the general level of price will change. We can explicit this idea as follows:

If an oil price shock shifts the general level of prices by increasing production costs, it decreases the components of total demand such as real national consumption, real investment expenditure, real government expenditure, and the real transport cost of exports and imports. Therefore, the real value of national expenditure decreases du to inflation. If the relative increase in the imported oil price exceeds the relative rise of exported goods, then a deficit will occur in the trade balance or the net exports of a country $(\mathrm{X}-\mathrm{M})$. Consequently, the federal real gained income of energy consumers will fall. Therefore, their demand for goods and services decreases. Such a decrease in demand will cause the demand curve to fall. This occurs mostly in industrial countries, which happen to also be the major importers of oil. The final result can be: a reduction on the production or the GDP, with a price level that can be the same as initially (before the oil shock) or lower, if we suppose a passive, or no change, in the monetary and fiscal policies)

\section{III.Economic Growth and oil shocks}

In addition to labor and capital, energy is also considered as factor of production. Therefore, production would be a function of labor, capital and energy.

$$
Q=f\left(K_{,} L_{s} E\right)
$$

Where, $Q$ measure the GDP, $K$ measure the stock of capital, $L$ the stock of labor, and the stock for energy is E. Therefore, any change on the quantity of Labor, Capital or Energy leads to the alteration of levels of production.
Furthermore, there are direct relationships between the use of such elements and the level of production. In other words, a rise (decrease) of each of the foregoing elements leads to an increase (decrease) in production. In the above function, a positive variation of: $\mathrm{K}, \mathrm{L}$ and $\mathrm{E}$ leads to a positive modification of $\mathrm{Q}$.

In addition, utilization of energy from different sources such as oil, gas, coal and electricity, is itself a reverse function of the price level of energy sources. In other words, an increase in energy prices lead to a fall in energy as input in the production function, which in turn results in a decrease in production.

$$
E=E\left(P_{0}, P_{g}, P_{C^{\prime}} P_{\theta}\right)
$$

With, $P_{0}$ for oil price, $P_{g}$ for gas price, $P_{c}$ for coal price and $P_{e}$ for electric price.

Energy considered as a factor of production that has a down turn demand curve relatively to price of energy. Consequently, partial derivative between $E$ and each price is negative.

An increase in oil price may lead to the substitution of oil by other sources of energy. Therefore, as it is a production factor, it will have short-term effects on the increase of production costs and will lead to the reduction of real production of oil importer countries. In the long run too, it leads to a rise in costs; the rate of which will depend on the ability of other sources to replace oil. If ability to substitute exists, such price increases will have no important effect on costs. To show the primary and secondary effects of alteration of energy prices, we can deduct energy costs from gross product to determine net product as follows:

$$
y=Q-P_{E} E
$$

The net product is $y$ and $E$ is the amount of energy used to monetary product $Q$ and $P_{E}$ represent price index of energy.

\section{Welfare hidden Impact of oil Prices}

The bulk of petroleum is consumed indirectly through household consumption of other goods and services that use petroleum products as inputs. Therefore, the welfare effect of higher oil prices and lower subsidies on household real incomes is as two form:

- direct effect of higher prices for petroleum products consumed by households

indirect effect arising from higher prices for other goods and services, using energy or petroleum as input in their production process. So, these higher prices will be passed indirectly to households.

Calculating the direct effect or hidden effect, and how it is distributed across income groups, essentially requires information on the level of direct consumption of various petroleum products (gasoline, diesel, and liquefied petroleum gas) or the budget share expenditure of households across the national income distribution. The main source of information is typically a household survey containing expenditures by each household on individual oil products. A "first-order" measures the direct real income effect of oil price and can be calculated 
as follows: - For each household we calculate the budget share of fuel expenditure items, i.e., fuel expenditures divided by total household consumption. Multiplying budget shares by the percentage increase in price due to the increase in fuel prices gives a first-order estimate of the real income effect of the price rise, which assumes that fuel consumption stays fixed. We assume that there is a total pass-through of pricing. This means, that the increase of energy prices on the supply cost are directly transmitted to consumers and there is no subsidies from the government. This overestimates the real income effect since, in practice, households can reduce this impact by substituting away from fuel.

The incidence of the real-income effect can be analyzed by examining how the magnitude of the effect varies across the income distribution. Typically, household per capita consumption, possibly adjusted for family composition, is taken as the best proxy of household welfare.

We can then analyze the hidden incidence of the real income effect by calculating the average percentage real income loss. If the percentage real income loss is higher (lower) for low-income households, then the incidence is said to be regressive (progressive). Recent studies showed that the greatest budget share of the poorest households are devoted for fuel. Therefore, the increase of price of this type of energy, has a great impact on poor households.

Put differently, the budget share gives a first-order approximation of the welfare impact of price change, or the amount of money required to maintain unchanged the utility level of the household.

For a given product, the share of spending on that product in total expenditure corresponds to the price elasticity of real income or total spending assuming the volume of demand constant. Put differently, the budget share gives a first-order approximation of the welfare impact of price change, or the amount of money required to maintain unchanged the utility level of the household.

$$
\frac{d y}{y}=b_{i} \frac{d p_{i}}{p_{i}}
$$

where $y$ is the level of income or expenditure, $b_{i}$ is the share of spending on good $i$ in total expenditure and, $p_{i}$ is the price of good $i$.

For instance, if diesel account for 10 percent of total spending of a household, the direct effect of a 10 percent increase in diesel price would be a 1 percent decline in household real income or a corresponding increase in household real expenditure. Since households can consume energy products or goods as gasoline, fuel, diesel, the overall direct effect is the sum of the direct effect associated with each fuel product.

$$
\frac{d y_{d i r}}{y_{\text {dir }}}=\sum_{i=1}^{m} b_{i} \frac{d p_{i}}{p_{i}}
$$

Where $m$ is the total number of goods directly depend to energy products (gasoline, fuel, diesel).

Identifying the magnitude of the hidden indirect effect requires an estimate of the effect of higher fuel costs on the prices of other goods and services consumed by households. These price effects can be estimated using an input-output table of the economy showing the energy intensity of each sector and a simple model of the effect of higher fuel costs on prices. As with the direct effect, the indirect real-income effect can be calculated by multiplying the budget shares of the various goods and services by the estimated percentage price increases in these sectors. The incidence of the indirect effect can be determined by estimating the effect separately for households across the national income distribution.

$$
\frac{d y_{\text {indir }}}{Y_{\text {indir }}}=\sum_{i=m+1}^{n} b_{i} \frac{d p_{i}}{p_{i}}
$$

We have $n-m$ as the number of non-fuel products. With $n$ is the number of goods produced using energy as inputs.

The total real income effect is calculated as the sum of the direct and indirect real income effects, and the incidence can also be determined by calculating the average effect for households in different parts of the income distribution. In practice, reflecting the high proportion of fuel consumed in the production and distribution of goods and services, the indirect effect accounts for over half of the total effect.

\section{Macroeconomic transmission channels of oil price shocks}

The several researchers have supported the view that the countries with stronger trade relationships have similar business cycles. For instance, we can state that the shocks that occur in one country can be transmitted to all sectors in that country spatially to agricultural sector. In addition, oil price shocks can be transmitted to another country if they have intensive trade linkages. According to the reference [15] the hidden effects of oil price were significant at the case of integrated

countries. The results of the study suggested that, it is quite advantageous for the industrial countries to trade with the developing countries, due to the high growth capacity of developing countries. On the other hand, the developing economies gain from trading with the industrial countries because of the higher relative income levels in the industrial countries. To explain our idea, we present the study by Tilak Abeysinghe and Kristin Forbes (2005) that used a structural VAR model and 11 Asian countries, also confirmed the fact that trade linkages is very significant aspect in case of transmitting the effects of shocks occurred in one country to its main trading partners. For developing countries in which agricultural sector has a great part of the national GDP (Gross Domestic Product), oil price shocks are directly and indirectly transmitted to social welfare through agricultural goods.

Oil price changes are almost generally accepted as a significant factor that affects different economies of oilexporting and oil-importing countries. According to the study by Weiqi Tang, Libo Wu and Zhong Xiang Zhang (2009) there are several channels through which oil prices 
affect an economy and macroeconomic variables: interest rate, output and investment. According to the theory oil prices affect the macroeconomic variables through these six transmission channels: 1) supply-side shock effect; 2) inflation effect; 3) real balance effect; 4) the unexpected (uncertainty) effect.

Supply-side shock effect - From this perspective oil is described as direct input of production process. When local and national oil price increases it automatically affects the output through the rising production costs. Consequently, a lower productivity decreases the total output and increases the unemployment. This transmission process scenario is typical for an oilimporting country. For an oil-exporting economy higher revenues as a result of the oil price shocks can contribute the increases in investment opportunities, which will boost the output and decrease the unemployment.

Inflation effect - Oil price shocks also trigger the inflation in economy. The prices of agricultural goods will increase. As it was mentioned, oil price shocks increase the costs of production, which is considered as a price shock therefore. For developing countries, oil prices shocks make the economy more vulnerable due to the great part agricultural sector. This vulnerability calculated according to EVI indicator ${ }^{1}$.

Real balance effect - Through this transmission channel, an oil price shock impacts money demand. As an example, consumers tend to borrow and not to save, it increases the interest rates and decreases the demand for cash.

The unexpected (uncertainty) effect - The investment demand of both consumers and producers is affected through the uncertainty channel of an oil price shock. The future investment plans can be postponed if people do not know if the oil prices will go up or down. After that, the uncertainty causes the Investment demand to decrease.

\section{VI.Hidden impact of oil price volatilities: the case of Tunisia}

In this section, we resume a limited works done on the effects of oil price shocks on oil importing and oil dependent economies such Tunisia. The most important and significant research related to the effects of oil price shocks on economic activity and macroeconomic variables was done through the example of the US by [12]. In his papers, they showed that there is a strong relationship between oil price changes and economic growth of 11 Asian and OECD countries. In other words, an essential negative correlation between the oil price increases and the economic recessions in some countries was determined. Another not less significant aspect of oil price increases is that oil supply interruptions is a good prediction tool for GDP decrease, hence, it can cause the economic slowdowns. However, after the later research by [7], it was stated that there was a negative correlation in the case of oil price decreases and national GDP for the United States of America case.
Another interesting [9] studied the correlation path between the oil price shocks and economic growth during the period of 1982-2008 in Greece, which is a highly oil dependent country. Accordiong this study, the oil consumption was $64 \%$ of the total energy consumption in Greece in 2006. A statistic approach with time series equation were used to examine the relationship and possible asymmetries between oil prices and economic activity. The results stated that more than $3 \%$ month to month increases in oil prices and oil price volatility more than $2.4 \%$ during a year negatively affect the economic activity in Greece.

\section{Statistical approach and database}

To start the statistical development of direct and indirect impact on economy let us see the tendencies of oil prices over time from the $90^{\text {th }}$ to 2015 . Next graphic (figure 1) shows this evolution:

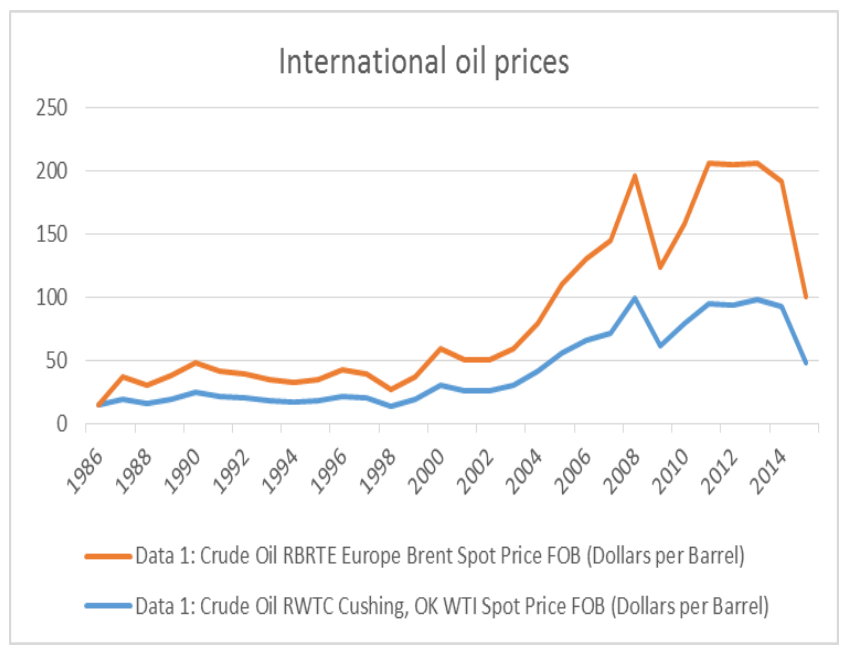

Figure 1. Annual modification of crude oil prices was done day by day from 1987 to 2017 .

Thus, if we measure the daily growth rate of oil prices, and the number of positive and negative growth each year, we can represent figure 2' as follow:

number of positive and negative groth days of oil prices

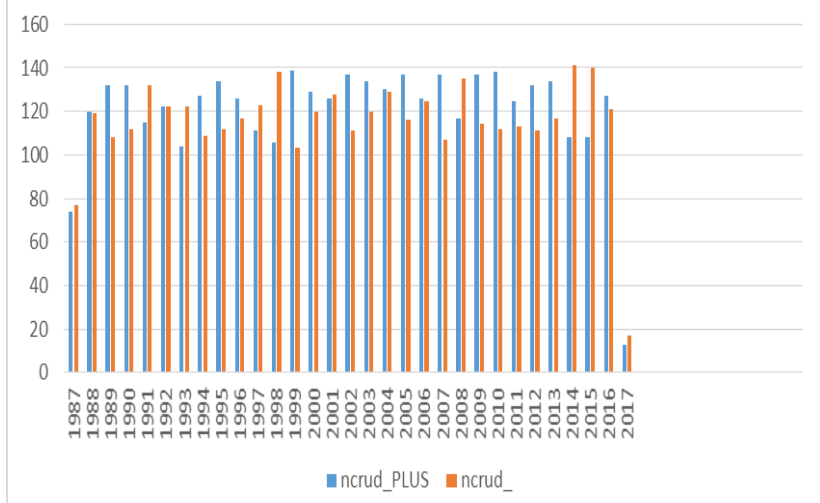

Figure 1. The number of positive and negative growth each year 
With NCRUD_plus is the number of days in which we have growth of oil prices, and NCRUD_ is the number of days in which we have negative growth oil prices.

The net result of the number of modification days is positive. The number of days in which we have growth of oil prices is more than the number of days with negative growth. Figure 1', shows this result:

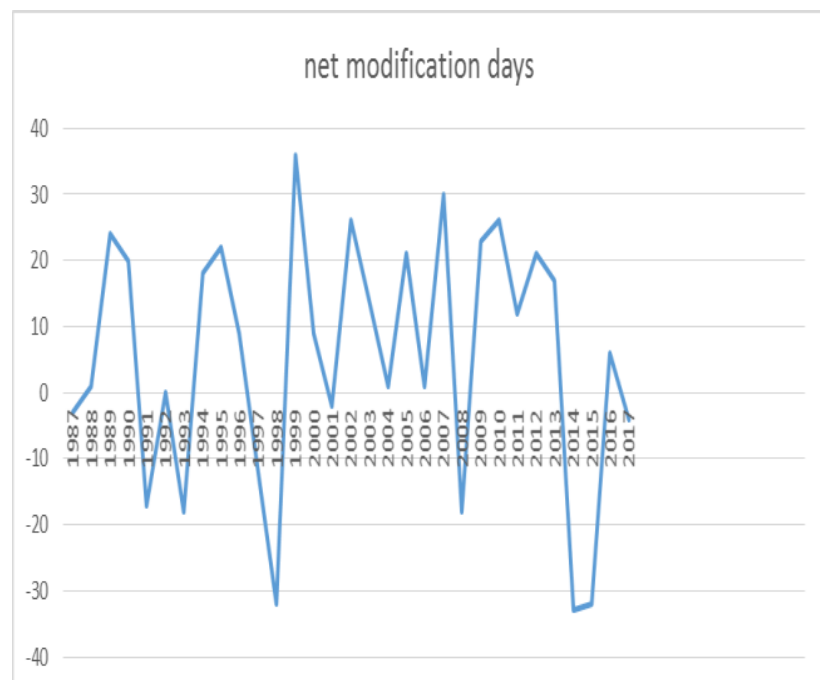

Figure 1. The number of days in which we have growth of oil prices is more than the number of days with negative growth

According to Tunisian indicators: annual GDP in national currency converted to U.S. dollars and annual real growth rate, we can represent figure 2 and figure 3 using INS database.

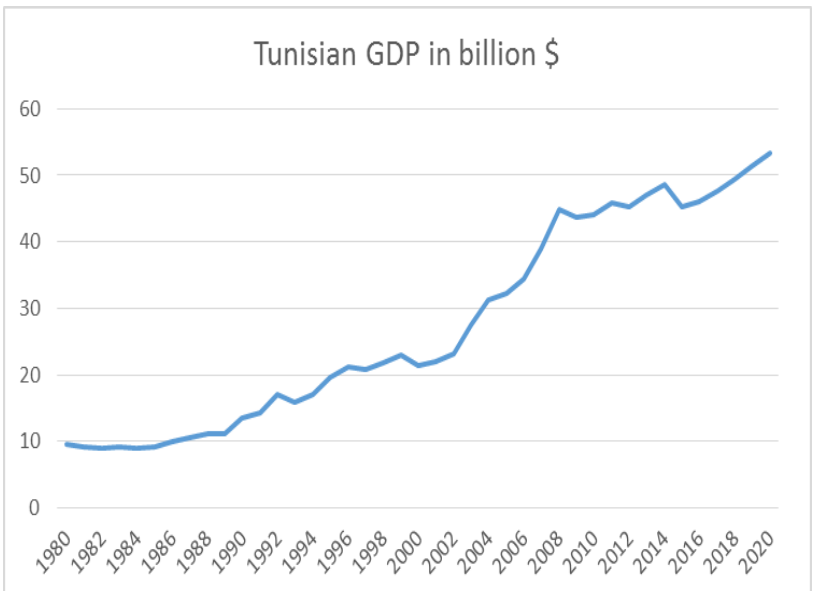

Figure 2. Annual GDP in national currency converted to U.S. dollars and annual real growth rate

\section{Tunisian growth rates}

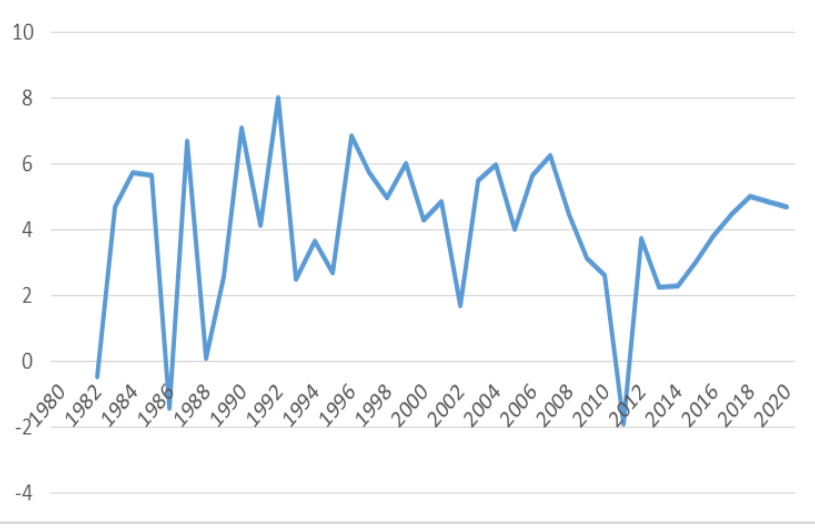

Figure 3. Annual GDP in national currency converted to U.S. dollars and annual real growth rate using INS database.

Using descriptive analysis we cannot easily see that there is direct and significant dependence between the tendency of oil prices and growth rates of national GDP in Tunisia. We add that Tunisia is one of developing countries which subsidies energy products. Therefore, oil or energy choc are not transmitted directly to domestic prices. However, the choc is transmitted via a more budget deficit. In addition, we can represent figure 4 in order to explain how Tunisian GDP vary according to petroleum prices. In figure 4 , we represent the tendency of Tunisian national investment per GDP (NID_NGDP ${ }^{2}$ ) and national saving over time. We can see that there is a gap from 2010 until now between NID_NGDP and (national domestic saving per GDP) NGSD_NGDP.

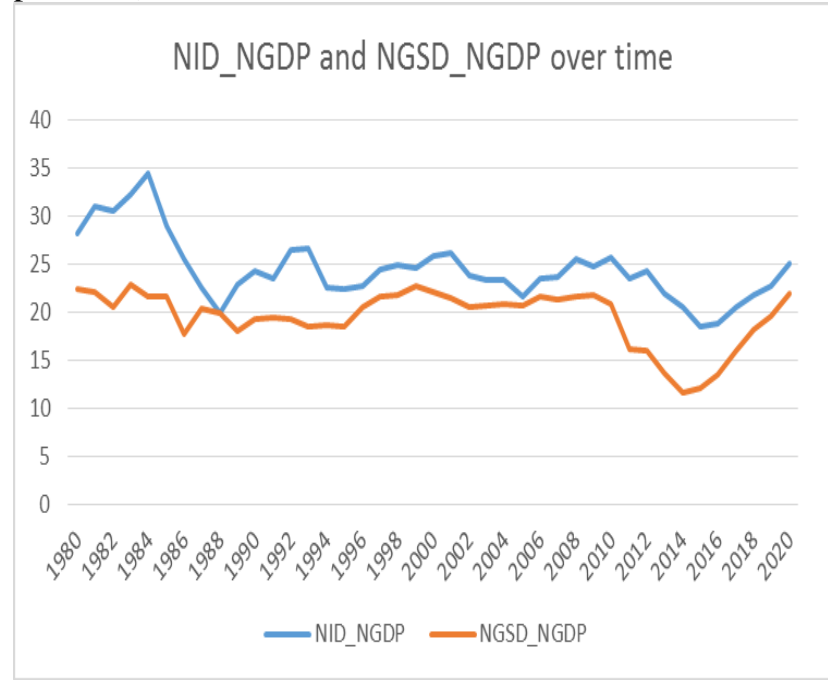

Figure 4. The tendency of Tunisian national investment per GDP (NID_NGDP) and national saving over time 
In order to detect the direct and indirect effects of oil prices on the social welfare, we adopt a descriptive statistical method and the estimation of time series equations. This method differs from the approaches of IMF studies using a-theoretical approaches under VAR models.

Our approach differs radically from IMF studies that aim to detect impacts through VAR modeling because in Tunisia the price system does not reflect production costs due to the fuel subsidy policy. Tunisia is the start point of the Arab Spring. There has been a restructuring of the institutional and political system from a presidential regime to another hybrid regime supported by the international financial institutions including the IMF. The latter institution has encouraged all policies to reduce petroleum subsidies adopted by governments. Consequently, the Tunisian government has adopted a policy of automatic correction of fuel prices.

The database used is World Bank data and International Energy Statistics (IES) during the period 1980-2020. The values of 2017, 2018, 2019 and 2020 are estimates by the World Bank. Missing data are estimated by moving average.

We introduce in this paper the variable EVI, which measures economic vulnerability according to the FERDI database. The EVI is the simple arithmetic average of 2 sub-indexes ${ }^{3}$ :

The exposure sub-index, which is a weighted average of 5 component indexes: population size $(25 \%)$, remoteness from world markets (25\%), exports concentration $(12.5 \%)$, share of agriculture, forestry and fishery in GDP $(12.5 \%)$ and the share of population living in low elevated coastal zone $(25 \%)$.

The shocks sub-index, which is a weighted average of 3 component indexes: the victims of natural disasters $(25 \%)$, the instability in the agricultural production $(25 \%)$, and the instability in exports of goods and services $(50 \%)$.

Components are built on different kinds of primary data (number, percent, index), which are normalized through a min-max procedure, to get component indices ranging from 0 to 100 , with high scores corresponding to a high level of vulnerability. The sum of components' weights equals 1 so that the EVI is also lying between 0 and 100 .

The variable $X$ measures the share of agriculture in the national GDP according to the FERDI database. $Y$ measures the number of days in which an increase in crude oil prices from IES database. The variable NGDPD is the current GDP in dollars. PCPI is the general index of consumer prices. LUR is a measure of unemployment rate according to the World Bank. BCA is the current balance account, according to the World Bank database.

By calculating the correlation coefficient between different variables, we provide the following matrix:

\begin{tabular}{|c|c|c|c|c|c|c|c|}
\hline & & $y$ & $\lambda$ & PCPI & EVI & BCA & LUR \\
\hline & & & & & & & 00040 \\
\hline 1 & & 1,000000 & & & 1860 & 7818 & (21112? \\
\hline X & & No & 1.00000 & & .0950000 & $0.300 / 10$ & 0.41159 \\
\hline rur & & & & & & & \\
\hline$=$ & & & & & & & \\
\hline $\mathrm{BCA}$ & & & 0.5007 & $v_{1}$ & 0.926899 & 1.00000 & 0.248 \\
\hline & & 0.3111239 & viti & 0.3025252 & 0.094660 & .0 .248040 & 1.000 \\
\hline
\end{tabular}

According to this matrix, there is a strong correlation between GDP and all variables. However, the upward movements of oil price days (Y) positively modify the Tunisian GDP measured in current US dollars. At the same time, we note that the variable $\mathrm{Y}$ is negatively correlated with the economic vulnerability index (EVI). Y Has no remarkable effect on the current balance of payments (BCA). Upward movements of oil price days (Y) is creator of inflation and he is not creator of unemployment.

It seems paradoxical that $\mathrm{Y}$ generates growth by positive co-rotation between $\mathrm{Y}$ and NGDPD, bit it is normal to find a negative correlation between energy price measurement $(\mathrm{Y})$ and the share of agriculture in national GDP (X). This result seems logical for a country like Tunisia, which is a producer of crude oil and importer of petroleum derivatives. The upward movements in Brent crude oil prices affect positively the national GDP through other hidden channels: it is an indirect impact of oil on the Tunisian economy.

From the remarks of the correlation matrix, the following regressions estimated by OLS can be provided and givehidden measurement of the impact of oil prices to macroeconomic variables:

Table 2: impact of oil prices on vulnerability, National GDP and inflation

\begin{tabular}{|l|l|l|l|}
\hline & $\begin{array}{l}\text { Equation 1 } \\
\log (\mathrm{EVI})\end{array}$ & $\begin{array}{l}\text { Equation 2 } \\
\log (\text { NGDPD) }\end{array}$ & $\begin{array}{l}\text { Equation 3 } \\
\text { Log(PCPI) }\end{array}$ \\
\hline $\log (\mathrm{Y}(-1))$ & 0.089506 & & 0.284842 \\
\hline $\operatorname{ar}(1)$ & 1.103476 & & \\
\hline $\mathrm{c}$ & 3.012979 & 11.81396 & 3.368298 \\
\hline $\begin{array}{l}\log (\mathrm{EVI}(- \\
1))\end{array}$ & & -2.709354 & \\
\hline $\mathrm{ma}(1)$ & & & 0.841762 \\
\hline $\mathrm{R}^{2}$ & 0.903996 & 0.500136 & 0.864299 \\
\hline F statistc & 94.16206 & 22.01198 & 82.79918 \\
\hline
\end{tabular}


NB. All parameters are elasticities. They are statistically significant at a risk of $1 \%$. The three equations are globally significant according to the Fisher criterion.

The linear equations 1,2 and 3 prove the results of the correlation matrix. A $1 \%$ increase in oil prices makes the Tunisian economy more vulnerable. This vulnerability negatively affects current national GDP growth. A $1 \%$ increase in economic vulnerability translates into a $2.7 \%$ drop in economic growth. According to Equation 1, a 1\% increase in oil prices generates $0.285 \%$ inflation.

\section{Conclusion}

The volatility of fuel prices has serious impacts on the Tunisian economies because they are not direct. The impact on social welfare and economic growth is indirect. It is apparent on consumer prices by making the Tunisian economy more vulnerable. The effect of international fuel prices and volatility are more severe for Tunisia and will only be apparent over the long term, through the negative impact to the balance of payments (current account) and the rise in prices by damaging the agricultural sector. The hidden negative impact of crude oil prices on national GDP is serious because in Tunisia there is an energy subsidy policy that distorts the precise calculation of the production costs of goods and services. To remedy this problem, the IMF (International Monetary Fund) proposes to the Tunisian authority to review the subsidy policy and to adopt a pollution control policy and (the efficiency price system).

\section{References}

[1] D. Coady, M. El-Said, R. Gillingham, K. Kpodar, P. Medas, and D. Newhouse,The Magnitude and Distribution of Fuel Subsidies: Evidence from Bolivia, Ghana, Jordan, Mali, and Sri Lanka, IMF working paper, wp 06/247, 2006.

[2] E. Papapetrou, Oil price asymmetric shocks and economic activity: the case of Greece, University of Athens, Department of Economics, Athens, Greece and Bank of Greece, Economic Research Department, 2009.

[3] F. Fabrizio, A. Goumilevski, and K. Kpodar, A New Tool for Distributional Incidence Analysis: An Application to Fuel Subsidy Reform, IMF working paper, 2015.

[4] F. Taghizadeh-Hesary, N. Naoyuki Yoshino, Macroeconomic Effects of Oil Price Fluctuations on Emerging and Developed Economies in a Model Incorporating Monetary Variables. ADBI Working paper series, working paper $\mathrm{N}^{\circ} 546,2015$.

[5] FH. Taghizadeh, N. Yoshino, G. Abdoli, and A. Farzinvash,"An Estimation of the Impact of Oil Shocks on Crude Oil Exporting Economies and Their Trade Partners", IMF working paper, 2013.

[6] HC . Bjørnland, Oil price shocks and stock market booms in an oil exporting country, working papers from Norges Bank $\mathrm{N}^{\circ} 16,2008$.

[7] HG. Huntington, Oil Shocks and Real US Income, Energy Modeling Forum Stanford University Stanford, CA 943054026, 2007.
[8] J. De Haan, R. Inklaar, R. Jong-A-Pin, Will business cycles in the euro area converge? A critical survey of empirical research, Journal of Economic Surveys Vol. 22, No. 2, 2013, pp. 234-273.

[9] M. Balcilar, The Impact of Oil Price on South African GDP Growth: A Bayesian Markov Switching-VAR Analysis, University of Pretoria Department of Economics Working Paper Series, 2014.

[10] M. Closset, S. Feindouno, and M. Goujon, Human Assets Index Retrospective series: 2013 updat, Working paper fondation pour les études et recherches sur le développement international.

[11] R. Jiménez-Rodríguez, M. Sánchez, Oil price shocks and real GDP growth empirical evidence for some OECD countries, European Central bank, Working Paper Series, $\mathrm{N}^{\circ} 362,2004$.

[12] T. Abeysinghe K. Forbes, Trade Linkages and OutputMultiplier Effects: a Structural VAR Approach with a Focus on Asia, Review of International Economics, 13(2), 356-375, 2005.

[13] T. Abeysinghe, Estimation of direct and indirect impact of oil price on growth, Economics Letters 73, 2001, pp 147153.

[14] T. Clements, H. Rainey, et al, An evaluation of the effectiveness of a direct payment for biodiversity conservation: The Bird Nest Protection Program in the Northern Plains of Cambodia, biological conservation $\mathrm{N}^{\circ} 157,2013$, pp 50-59.

[15] V. Arora, A. Vamvakidis, Asia and Pacific Department and Strategy, Policy, and Review Department China's Economic Growth: International Spillovers, IMF Working paper $\mathrm{N}^{\circ} 165,2010$.

[16] W. Tang, L. Wu, and ZX, Zhang, Oil price shocks and their short- and long-term effects on the Chinese economy, Energy economics 2010. doi:10.1016/j.eneco.2010.01.002. 